\title{
DETERMINATION OF SEX FROM THE STERNUM AND FOURTH RIB MEASUREMENTS (A CROSS-SECTIONAL STUDY) USING THORACIC COMPUTED TOMOGRAPHY (CT) IMAGES
}

\author{
Ola Abdel- Hady Sweilum ', Hobab K Alsebaey Galal'2, Rehab Mohammed Habib \\ 1_2Lecturer of forensic medicine and clinical toxicology, Menofia university, Shebin El Kom, \\ Egypt, ${ }^{3}$ Lecturer of radiodiagnosis, Menofia university.
}

\begin{abstract}
Background: Several causes may destroy the skeletal remnants. Environmental causes, blasts, decomposition, and traumatic destruction may impede identification of bones. Furthermore, some forensic science researches showed inconsistency in using skull and pelvis bones in gender identification. In progressive skeletal destruction, the integrity of sternum may be conserved. In the postmortem duration, morphometric investigations of the sternum can be done by using radiological means. Aim of the work: This study was done to assess the sensitivity of sternal and 4th rib measurement analysis for sex determination in Egyptian population. Subjects and methods: CrossSectional study of thoracic Computed Tomography (CT) images of 261 adult Egyptians arrived at Menoufia university hospital. Meso-sternum length (SL), Manubrium length (ML), Sternebra 1 width (MS1), Sternebra 3 width (MS3), $4^{\mathrm{TH}}$ Rib (its width at the level of costochondral junction) were measured. Differences between genders were detected by student $t$-test. Results: All sternal and forth rib measurements are significantly higher in males. The highest sensitivity and specificity values for sex discrimination were identified in SL as the sensitivity was $90.6 \%$ and specificity was $70.6 \%$.

Sex equation $=-\mathbf{1 3 . 1 3 4}+(\mathrm{SL} * \mathbf{0 . 0 6})+(\mathrm{ML} * \mathbf{0 . 1 1 1})+(\mathrm{MS1} * \mathbf{0 . 0 4 5})+(\mathrm{MS3} * 0.024)$ $+\left(4^{\text {th }}\right.$ rib*0.092). Conclusion: The sternum represented a reliable bone for sex determination in Egyptian population, based on a CT scan. The data generated from morphometric sternum studies are population specific data. Researchers can use a rapid and easy CT scanning for sternum and fourth rib as an effective method for sex identification. Recommendation: -we need to increase the number of conducted studies using radiological methods with proper analyses, as we can add other bones for forensic anthropologic evaluation. - As there are ethnic differences within national populations appeared in previous studies outside Egypt, we recommend other studies on the same bone in other Egyptian areas. - Use the equation of the sternal bone and the fourth rib measurement in determining sex.

Keywords: Sternal measurements, Sex determination, Computed Tomography, sex equation.

\section{INTRODUCTION:}

There are characteristic anthropological and biological factors that can be used for identification of an individual. Bone being resistant to putrefaction and damage caused by animals can be used for identification

and can help in estimation of age, gender and race (Mohit Gupta, et al., 2014). Significant data for human proof of identity procedures have been provided by anthropometric researches of skeletal structure (Haglund and Sorg 2002).
\end{abstract}


Sex identification is very important compared with age and race identification as it excludes almost half of the population (Knight and Saukko 2004).

Several causes may destroy the skeletal remnants. Environmental causes, blasts, animals, decomposition, and traumatic destruction may impede identification of pelvis and skull bones. It is not always possible and easy to perform direct measurement analyses on skeletal remains (Spradley and Jantz 2011).

The main anthropological methods used for gender identification are either directly measuring the skeletal remains or by imaging techniques. The major problems to obtaining intact bones are; trauma, decomposition, and disappearance for different causes (Byers 2002).

Furthermore, some researches showed inconsistency in using skull and pelvis bones in gender identification (Krogman and İşcan 1986, Spradley and Jantz 2011).

In progressive skeletal destruction, Mass mortality may be caused specially

\section{SUBJECT \& METHODS}

This cross-sectional study was done on thoracic Computed Tomography (CT) of 261 adult Egyptians (general population) (159 male and 102 female) live in Menoufia governorate. Their mean age was $54.4 \pm 14.3$ years for male and $51.7 \pm 15.7$ years for female. Patients arrived to Menoufia university hospital and referred to radiology department to have CT scan for other reasons.

The study was approved by the ethical committee at Menoufia university and individual consent was waived (not necessary to be taken from each patient). Peoples with any sternal in terroristic blastic attacks, rapid identification is a crucial procedure and may be only one bone is found intact and all data should be collected from this bone.

Morphometric and radiological investigations of the sternum can be done in the postmortem duration, as sternum has a bony structural advantage having a strong structure and preserved integrity (Torwalt and Hoppa 2005; Ramadan et al. 2010; Osunwoke et al. 2010), it also provides accuracy of $80 \%$ or greater in morphometric analyses. Also, Data Bank of Forensic Anthropology was reported that the sternum and manubrium preserve its good state in $59 \%$ of forensic cases (Bongiovanni and Spradley 2012).

This study was done to assess the sensitivity of sternal bone and $4^{\text {th }}$ rib morphometric analysis for sex determination in a sample of Egyptian population. Choosing the sternum as the integrity of sternal bone may be conserved better than other bony skeleton and many previous studies were done on other body bones.

trauma or deformity (congenital or acquired), were excluded from the study.

Computed tomography images were taken by Toshiba 16 channel multi-slice CT scanner in Radiology department, Menoufia university hospital. Images performed with slice collimation $2.5 \mathrm{~mm}$, pitch 1 to 1.5 .

\section{Method:}

Measurements obtained from each patient by $\mathrm{CT}$ were:

- Meso-sternum length (MSL) or (SL): the distance from the sternal angle to the sagittal midpoint of the xiphisternal joint. 
- Manubrium length (ML): the distance from the jugular notch to the sagittal midpoint of the manubriosternal joint

- Sternebra 1 width (S1W) or (MS1): the distance between the left and the right first sternebra (depressions between the articulation notches for the second and third costal cartilage).

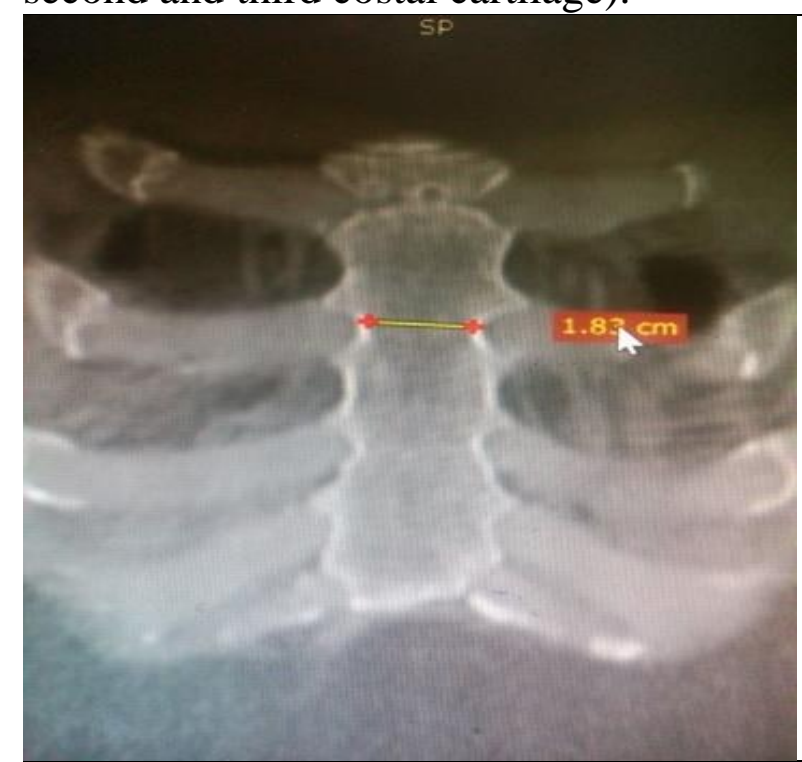

Figure 1: Male patient 57ys old, CT chest bone window with sagittal reformats showing sternebral 3 width $18.3 \mathrm{~mm}$.

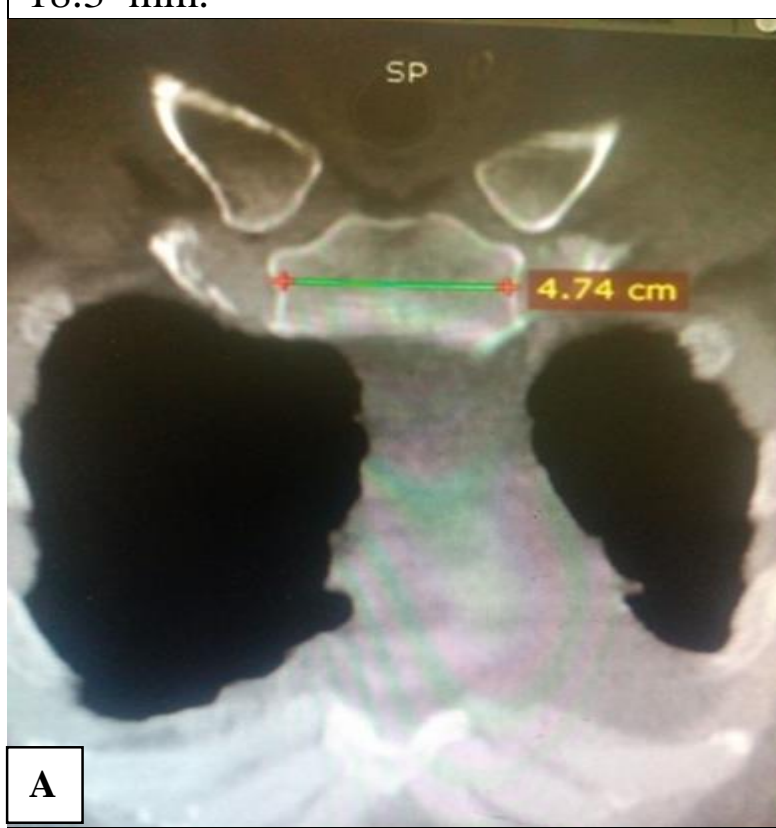

- Sternebra 3 width (S3W) or (MS3): the distance between the left and right third sternebra (depressions between the articulation notches for the fourth and fifth costal cartilage).

- $4^{\mathrm{TH}}$ Rib: its width at the level of costochondral junction.

All measurements were taken by CT (Figures 1-4).

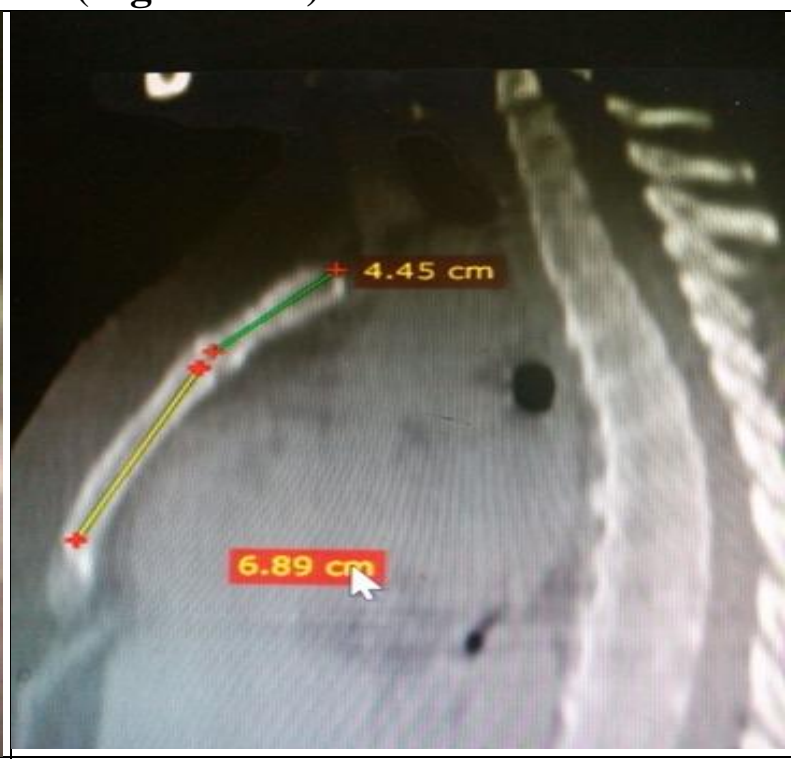

Figure 2: Male patient 63 ys, CT chest bone window with sagittal reformats showing : ML $44.5 \mathrm{~mm}$ and MSL 68.9 $\mathrm{mm}$.

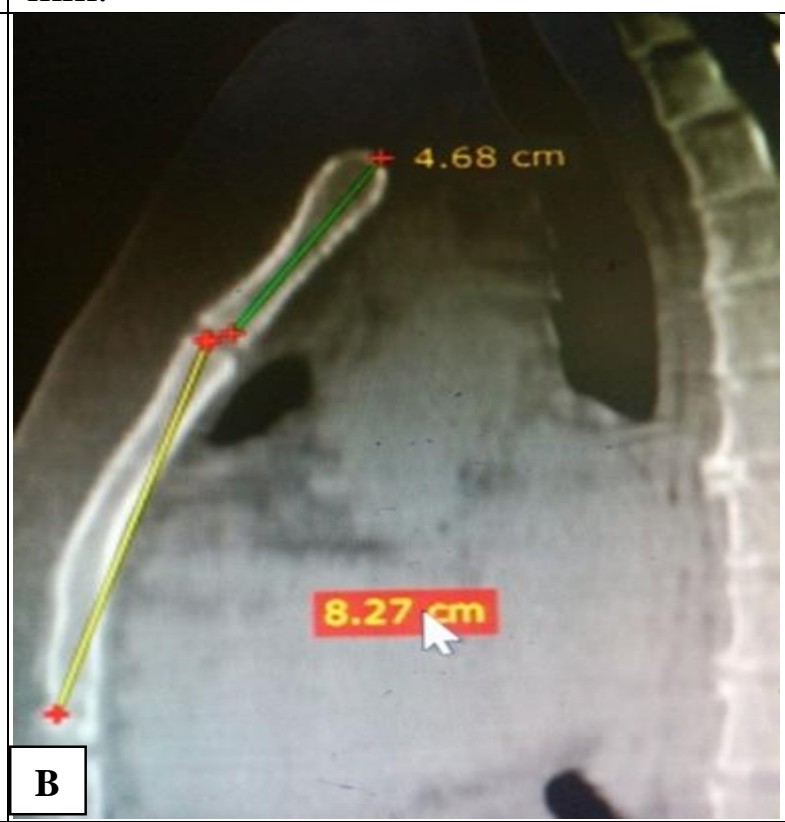

Figure 3: Female patient 55 ys, CT chest bone window with coronal (A) and sagittal (B) reformats showing: sternebral 1 width $23.3 \mathrm{~mm}$. ML $47.4 \mathrm{~mm}$ and MSL 82.7 $\mathrm{mm}$. 


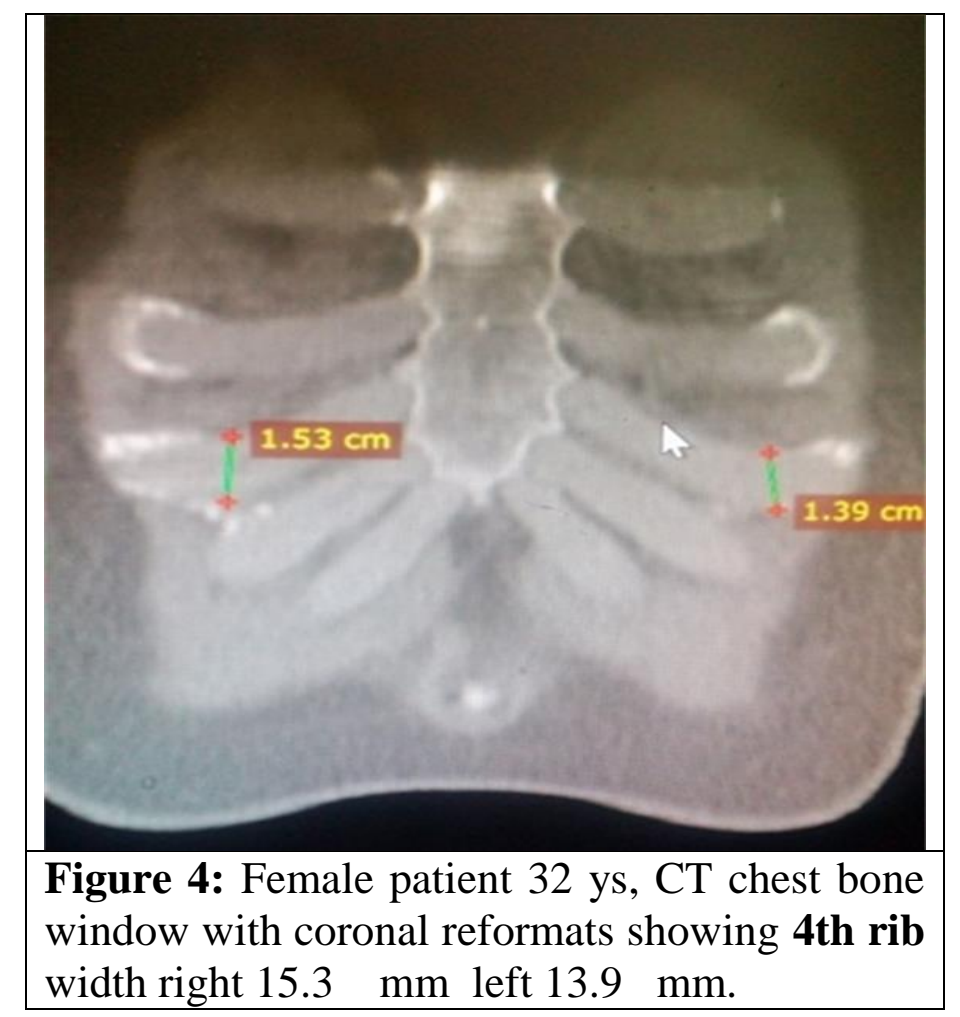

\section{Statistical analysis:}

Data were fed to the computer and analyzed using ibm spss software package version 20.0. (armonk, ny: ibm corp) (kirkpatrick la. And feeney bc. 2013) qualitative data were described using number and percent. The kolmogorov-smirnov test was used to verify the normality of distribution quantitative data were described using range (minimum and maximum), mean, standard deviation and median. Significance of the obtained results was judged at the $5 \%$ level.

The used tests were:

\section{Student t-test}

For normally distributed quantitative variables, to compare between two studied groups

receiver operating characteristic curve (roc)
It is generated by plotting sensitivity (tp) on y axis versus 1-specificity (fp) on $x$ axis at different cut off values. The area under the roc curve denotes the diagnostic performance of the test. Area more than $50 \%$ gives acceptable performance and area about $100 \%$ is the best performance for the test. The roc curve allows also a comparison of performance between two tests.

\section{accuracy}

Rate of agreement $=($ true positives + true negatives) / total tested x 100

odd ratio (or):

Used to calculate the ratio of the odds and $95 \%$ confidence interval of an event occurring in one risk group to the odds of it occurring in the non-risk group. 


\section{RESULTS:}

Table (1): Comparison between male and female as regard sternal and forth rib measurements

\begin{tabular}{|l|c|c|c|}
\hline & \multicolumn{2}{|c|}{ Gender } & \multirow{2}{*}{$\mathbf{p}$} \\
\cline { 1 - 3 } & $\begin{array}{c}\text { Male } \\
(\mathbf{n}=\mathbf{1 5 9})\end{array}$ & $\begin{array}{c}\text { Female } \\
(\mathbf{n = 1 0 2})\end{array}$ & \\
\hline Age (years) & & & \\
\hline Range & $19-80$ & $22-72$ & 0.162 \\
\cline { 1 - 3 } Mean \pm SD & $54.4 \pm 14.3$ & $51.7 \pm 15.7$ & \\
\hline SL & $99.3 \pm 9.4$ & $89 \pm 14.2$ & $<0.001^{*}$ \\
\hline ML & $51.7 \pm 6.6$ & $46.2 \pm 5.8$ & $<0.001^{*}$ \\
\hline MS1 & $25.1 \pm 3.9$ & $22.2 \pm 3.7$ & $<0.001^{*}$ \\
\hline MS3 & $29.2 \pm 5.1$ & $26 \pm 5.6$ & $<0.001^{*}$ \\
\hline $4^{\text {th}}$-rib & $9.1 \pm 1.4$ & $7.7 \pm 2.1$ & $<0.001^{*}$ \\
\hline
\end{tabular}

$t, p: t$ and $p$ values for Student $t$-test for comparing between the two groups

$*$ : Statistically significant at $\mathbf{p} \leq \mathbf{0 . 0 5}$

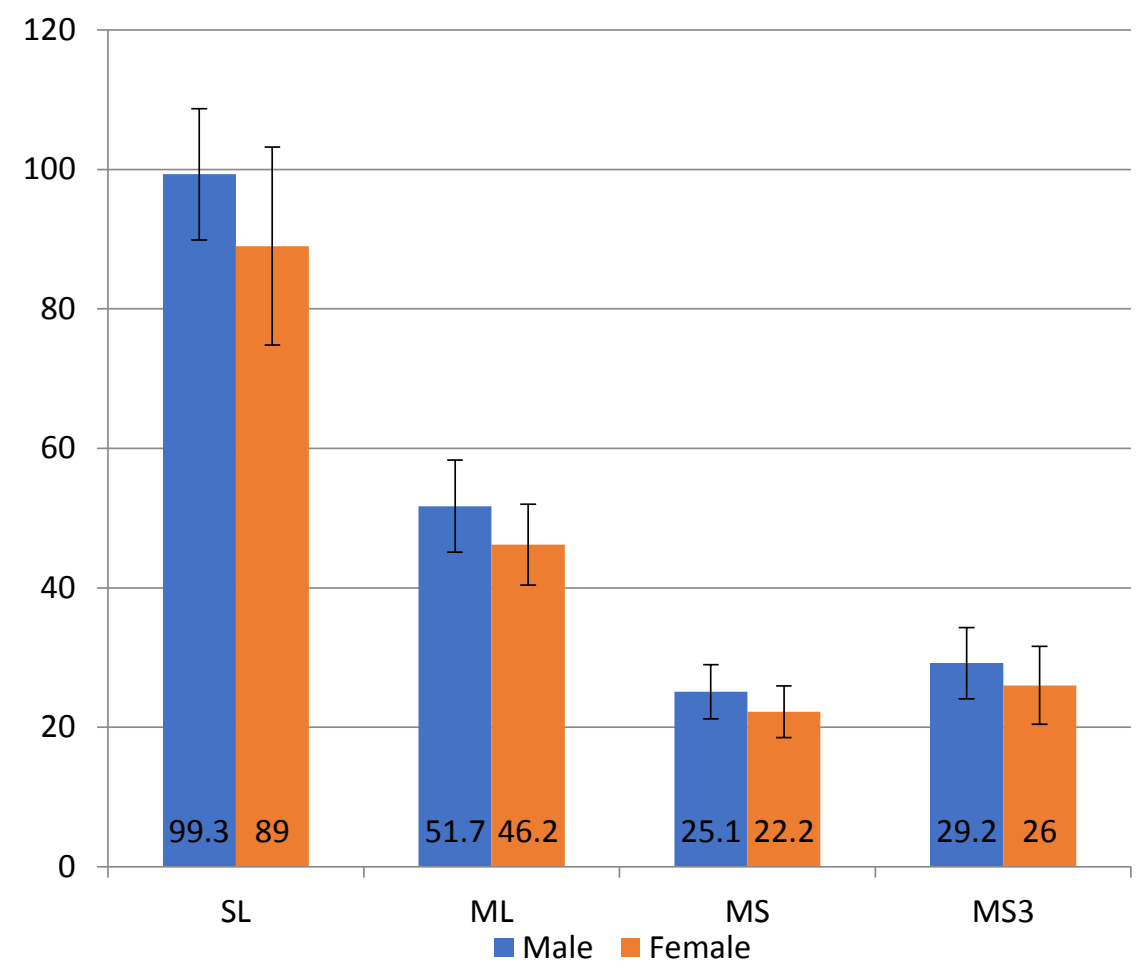

Figure (5): Comparison between male and female as regard sternal measurements 


\section{4th-rib}

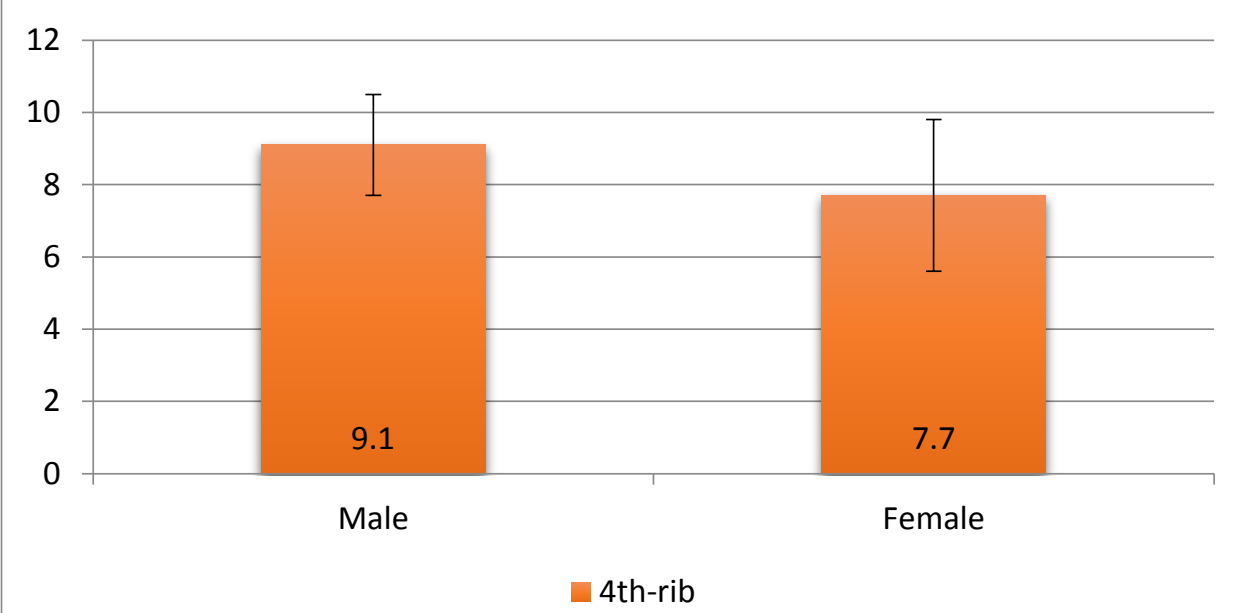

Figure (6): Comparison between male and female as regard forth rib measurement

Table (2): Sex equation with logistic regression

\begin{tabular}{|l|c|c|c|c|c|}
\hline & B & Sig. & OR & \multicolumn{2}{|c|}{ 95\% CI } \\
\cline { 5 - 6 } & & & & LL & UL \\
\hline SL & 0.060 & $<0.001^{*}$ & 1.061 & 1.027 & 1.097 \\
\hline ML & 0.111 & $<0.001^{*}$ & 1.118 & 1.058 & 1.181 \\
\hline MS1 & 0.045 & 0.393 & 1.046 & 0.943 & 1.161 \\
\hline MS3 & 0.024 & 0.434 & 1.025 & 0.964 & 1.089 \\
\hline $4^{\text {th }}$ rib & 0.092 & 0.350 & 1.097 & 0.904 & 1.331 \\
\hline Constant & -13.134 & $<0.001^{*}$ & & & \\
\hline
\end{tabular}

Sex equation $=-13.134+\left(S^{*} * 0.06\right)+(M L * 0.111)+(M S 1 * 0.045)+(M S 3 * 0.024)+$ $\left(4^{\text {th }}\right.$ rib*0.092).

Table (3): ROC analysis results

\begin{tabular}{|l|c|c|c|c|c|c|}
\hline Cutoff point & 4th-rib & MS3 & MS1 & MI & SL & Model \\
\hline Sensitivity & $83 \%$ & $>26.5$ & $>22.5$ & $>48.5$ & $>92.5$ & $\begin{array}{c}>0.146=\mathrm{ma} \\
\text { le }\end{array}$ \\
\hline Specificity & $59.1 \%$ & $64.7 \%$ & $75.5 \%$ & $79.2 \%$ & $83.0 \%$ & $88.7 \%$ \\
\hline P .value & $<0.001^{*}$ & $<0.001^{*}$ & $<0.7 \%$ & $73.5 \%$ & $70.6 \%$ & $82.4 \%$ \\
\hline NPV & $77.7 \%$ & $69.5 \%$ & $72.5 \%$ & $78 \%$ & $77.4 \%$ & $82.4 \%$ \\
\hline PPV & $66.9 \%$ & $67 \%$ & $68.1 \%$ & $75 \%$ & $75.7 \%$ & $88.7 \%$ \\
\hline AUC & 0.72 & 0.67 & 0.73 & 0.78 & 0.825 & 0.844 \\
\hline
\end{tabular}

SL accuracy for females $=82.4$

SL accuracy for males $=\mathbf{7 3 . 5}$

Model accuracy for females $=\mathbf{8 4 . 3}$

Model accuracy for males $=\mathbf{8 8 . 6}$ 

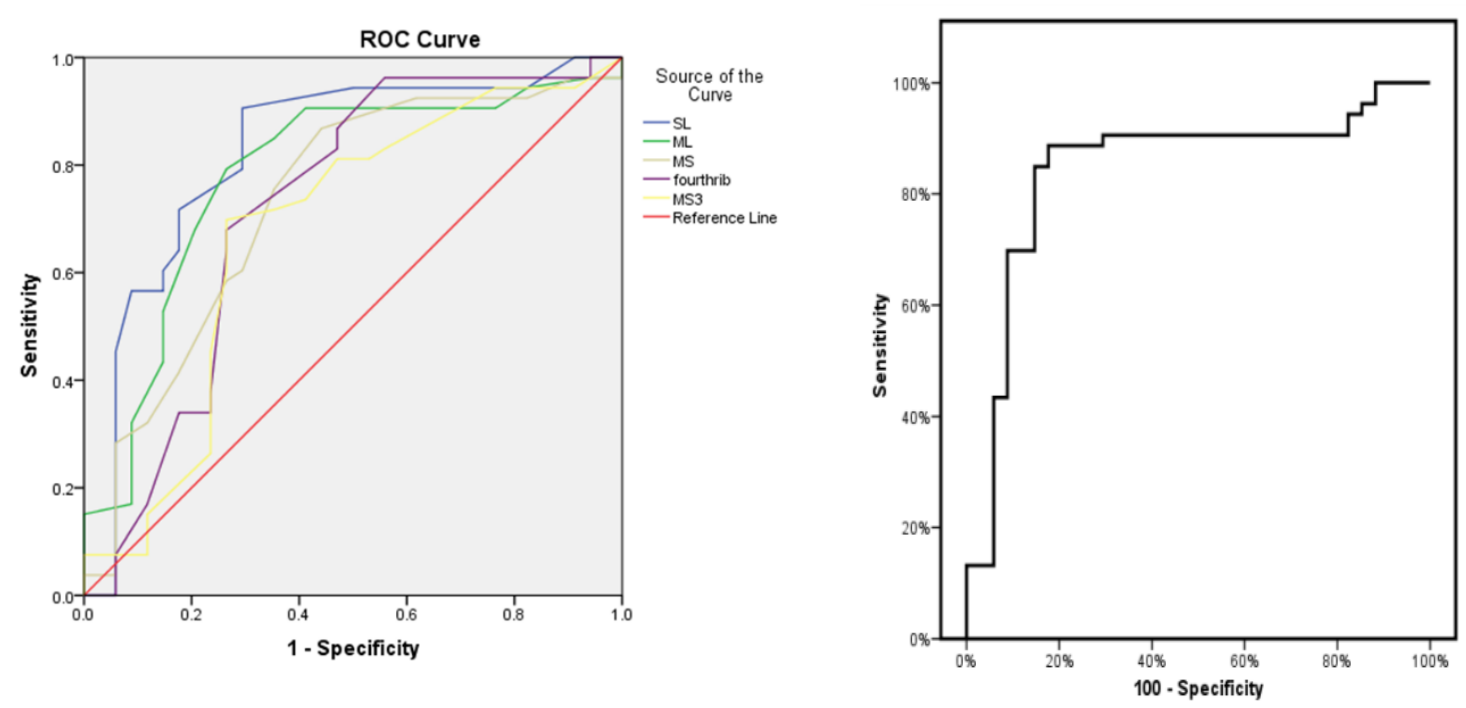

Figure (7): ROC curve of measurement

The present study is a crosssectional study carried on 261 adult Egyptian population (159 male and 102 female). The mean age \pm SD for males was $54.4 \pm 14.3$ years, while the mean age \pm SD for females was $51.7 \pm 15.7$ years. The mean values of sternal bone (SL, ML, MS1, MS3) and $4^{\text {th }}$ rib measurements (all measured in $\mathrm{mm}$ ) were higher in male compared with female and this difference was statistically highly significant $(\mathrm{P}$ value $<$ 0.001) (Table 1, Figures $5 \& 6$ ).

By logistic Regression analysis, we used the result values to generate a formula to determine sex between Egyptian population from sternal (SL, ML, MS1, MS3) and fourth rib measurements (Table 2)

The Equation for sex determination from sternal and fourth rib measurements is:

Sex determination $=-13.134+$ $\left(\mathrm{SL}^{*} 0.06\right)+(\mathrm{ML} * 0.111)+$ $(\mathrm{MS} 1 * 0.045)+(\mathrm{MS} 3 * 0.024)+(4 \mathrm{th}$ $\mathrm{rib}^{*} 0.092$ )

ROC analysis was used to determine the optimum values for sex determination. The optimum cut-off value was determined from sensitivity and specificity values. the sensitivity and specificity of each sternal bone measurement and fourth rib measurement used for sex determination.

Sensitivity of SL, ML, MS1, MS3 and fourth rib were $83 \%, 79.2 \%, 75.5 \%$, $71.7 \%$ and $83 \%$ respectively and specificity of SL, ML, MS1, MS3 and fourth rib were $70.6 \%, 73.5 \%, 64.7 \%$, $64.7 \%$, and $59.1 \%$ respectively. Comparing The sensitivity and specificity for each measurement separately, the optimum sensitivity and specificity values for sex discrimination were identified in the SL measurement ( $83.0 \%$ and $70.6 \%$ respectively) (Table 3 \& Figure 7).

While the model regression showed that the sensitivity and specificity of the five measurements together (collectively) in sex determination (SL, ML, MS1, MS3, and 4 the rib) were higher than each studied parameter separately (as it was $88.7 \%$ and $82.4 \%$ respectively) (Table $3 \&$ Figure 7 ).

The model of highest accuracy $(88.6 \%$ for males and $84.3 \%$ for females) for sex determination used all measurements (Sternal and $4^{\text {th }}$ rib) together. While the model accuracy for SL was $73.5 \%$ for males and $82.4 \%$ for 
females. This mean that using of all measurements (sternal and fourth rib) together results in more accurate sex determination.

\section{DISCUSSION}

This study included 261 computed tomography (CT) of adult Egyptian population (159 males, 102 female) live in Menoufia governate. The mean \pm SD age of male was $54.4 \pm 14.3$ years while the mean \pm SD age of female was $51.7 \pm$ 15.7 years.

A robust structure and preserved integrity of the sternum is the main structural advantages of this single bone. Also, CT scanning for the single bone remnant (as sternum) is considered an effective, easy, and rapid method for identification. (Sidler et al. 2007).

Jit et al. (1980) found that sex determined correctly by sternal bone in $89 \%$ male and $82 \%$ female. Dahiphale et al. ( 2002) found that $92 \%$ male and $87 \%$ female, their sex can be determined correctly by sternal bone.

Studying different sternal and forth rib measurements in the present study revealed that the mean values of SL, ML, MS, MS3, $4^{\text {th }}$ rib were higher in males compared with female and the differences were statistically highly significant $(\mathrm{P}<0.001)$. This difference is due to muscular activity and development of male more than female.

The results of the present study are in concordance with Ekizoglu et al. (2014), who found that the mean values of ML, SL, S1W (MS1), and S3W (MS3) were higher in males and the differences were also statistically significant $(\mathrm{P}<0.001)$ between both sexes.

Similar to this study, Gupta et al. (2014) reported that the mean lengths of the manubrium (ML) were higher in male compared with female $(40.639 \mathrm{~mm}$ and $37.286 \mathrm{~mm}$ respectively), this difference was statistically highly significant $(\mathrm{p}<0.000)$.

Ramadan et al. (2010) studied 340 CT views in a Turkish population and reported that the SL, ML, SW1(MS1), SW3 (MS3) sternal measurements were higher in male compared with females.

In the present study, SL had the highest accuracy between individual measurements (73.5\% in males and $82.4 \%$ in females). While accuracy of SL, ML, MS1, MS3, and 4th rib collectively was the highest $(88.6 \%$ for males and $84.3 \%$ for females).

Similar results were revealed by Ekizoglu et al. (2014), as they also observed that SL had the highest accuracy $(80.2 \%$ in females and $80.9 \%$ in males). while SI had the lowest sensitivity and specificity.

In contrast to the present study; Gupta et al. (2014) reported that the length of manubrium (ML) is the most reliable parameter for sex detection in central Delhi population. While Mohit V Changani (2014), observed that the combined SL and ML is the most reliable measurement for sex determination from the sternum.

In the present study, ROC analysis was revealed that sensitivity and specificity values for sex determination were higher in SL as a single measurement (as the sensitivity was $83 \%$ and specificity was $70.6 \%$ ), but all measurements together were more sensitive and specific $(88.6 \%$ and $84.3 \%)$.

Similarly, Ekizoglu et al. (2014) found that the optimum sensitivity and specificity values for sex discrimination were identified in the SL measurement (sensitivity of SL was $75.9 \%$ and specificity was $87.6 \%$ ). 
This is not agreeing with Torwalt and Hoppa (2005) and Ramadan et al. (2010), who found that only SA and fourth rib together are the best predictor for sex determination when using sternal bone and fourth rib.

However, the present study results including the sex determination equation applied on Egyptian population, as the sternal measurements showed ethnic variations between populations. This was proved by previous studies compared North and West Indian populations and reported larger female sternal measurements in North India and greater male sternal measurements in West India (Hunnargi et al. 2008, Singh and Pathak 2013, Menezes et al. 2009, Dahiphale et al., 2002). So, the sternal measurements can be used for population difference determination.

Population specific studies concluded that mean sternum measurements in South African and Indian populations (Macaluso 2010, Hunnargi et al. 2008) were lower than those of European (Marinho et al. 2012, Teige 1983, Ashley 1956, Franklin et al. 2012), US and Canadian populations (Spradley and Jantz 2011).

Macaluso et al. (2014) studied sex determination in a Spanish population and reported that a stepwise analysis of (ML, corpus sterni length, manubrium width, CSWS1, and CSWS3 (corpus sterni width at third sternebra), yielded a sex discrimination accuracy of $89.7 \%$.

\section{CONCLUSION}

The present study showed that Sternal Length (SL) is the most reliable parameter in sex determination if we use a single measurement. But the use of multivariate analysis technique (SL,
ML, MS1, MS3, and 4th rib) can be more sensitive and specific of sex determination. $\mathrm{CT}$ is a useful and accurate tool for sex determination by sternal bone.

\section{RECOMMENDATION}

1-we need to increase the number of conducted studies using radiological methods for sex determination, as we can add other bones for forensic anthropologic evaluation.

2- As there are ethnic differences within national population (appeared in previous studies outside Egypt), we recommend other studies on the same bone in other areas in Egypt.

3- Use the result equation of the sternal bone and the fourth rib measurements in determining sex.

\section{CONFLICTS OF INTEREST}

The authors declare that they have no conflicts of interest in the research.

\section{REFERENCES:}

Ashley, GT. (1956): "The human sternum: the influence of sex and age on its measurements." J Forensic Med 3:27-43.

Bongiovanni, R.; Spradley, MK. (2012): Estimating sex of the human skeleton based on metrics of the sternum. Forensic Sci Int; 219:2901-2907

Byers, SN. (2002): Introduction to Forensic Anthropology: fourth edition. A Textbook Boston: Allyn and Bacon.

Camps, FE. (1976): Gradwohl's Legal Medicine. Third Ed. ed. Bristol: John Wright \& sons Ltd.

Dahiphale, V.P.; Baheete B.H. and Kamkhedkar S.G. (2002): "Sexing the Human Sternum In 
Marathwada Region." J Anat. Soc. India 51 (2):162-167.

Ekizoglu, O.; Hocaoglu, E.; Inci, M. G. et al., (2014): "Sex estimation from sternal measurements using multidetector computed tomography." Medicine (Baltimore) 93 (27): e240. doi: 10.1097/md.

Franklin, D.; Flavel, A.; Kuliukas, A. et al., (2012): "Estimation of sex from sternal measurements in a Western Australian population." Forensic Sci Int 217 (1-3): 230.e15.

Gupta, Mohit, Anil Kumar, and SK Khanna (2014): "Determination of Sex from Sternal Bone In Central Delhi Population." J Indian Acad Forensic Med. 36 (3).

Haglund, WD. \& Sorg, MH. (2002): Advances in Forensic Taphonomy: Method, Theory, and Archaeological Perspective. New York: CRC Press.

Hunnargi; S. A., Menezes, R. G.; Kanchan, T.; Lobo S. W. et al., (2008): "Sexual dimorphism of the human sternum in a Maharashtrian population of India: a morphometric analysis." Leg Med (Tokyo). 10 (1):6-10.

Jit, I.; Jhingan V. and Kulkarni M. (1980): "Sexing the human sternum." Am J Phys Anthropol. 53 (2):217-24.

Kirkpatrick, LA.; Feeney, BC. (2013): A simple guide to IBM SPSS statistics for version 20.0. Student ed. Belmont, Calif.: Wadsworth, Cengage Learning.

Knight; Bernard and Pekka, J. Saukko (2004): Knight's Forensic pathology. 3rd ed. London New York: Arnold; Distributed in the
United States of America by Oxford University Press.

Krogman; Wilton Marion and M. Yaşar İşcan (1986): The human skeleton in forensic medicine. 2nd ed. Springfield, Ill., U.S.A.: C.C. Thomas.

Macaluso, P. J.; Jr. (2010): "The efficacy of sternal measurements for sex estimation in South African blacks.". Forensic Sci Int. 202 (13): 111.e1-7.

Macaluso, P. J.; Jr. and Lucena, J. (2014): "Estimation of sex from sternal dimensions derived from chest plate radiographs in contemporary Spaniards.". Int J Legal Med. 128 (2):389-95. doi: 10.1007/s00414-013-0910-z.

Marinho, L.; Almeida, D. ; Santos A. and Cardoso H. F. (2012): "Is the length of the sternum reliable for estimating adult stature? A pilot study using fresh sterna and a test of two methods using dry sterna.". Forensic Sci Int 220 (1-3): 292.e14.

Menezes, R. G.; T. Kanchan; Kumar, G. P.; Rao, P. P. et al., (2009): "Stature estimation from the length of the sternum in South Indian males: a preliminary study." J Forensic Leg Med. 16 (8):441-3.

Mohit V. Changani; Mayank D. Javia; Kulin A. Varma (2014): Determination of sex from various measurements of human sternum and manubrium in Gujarat population. J Res Med Den Sci. 2(1): 59-65.

Mohit Gupta; Anil Kumar; SK Khanna (2014): Determination of Sex from Sternal Bone In Central Delhi Population. J Indian Acad Forensic Med. July-September Vol. 36, No. 3. 
Osunwoke, E.A; Gwunireama, I.U; Orish, C.N.; Ordu K.S and I Ebowe (2010): "A study of sexual dimorphism of the human sternum in the southern Nigerian population." Journal of Applied Biosciences 26:1636 - 1639.

Ramadan, S. U.; Turkmen, N.; Dolgun, N. A.; Gokharman, D. et al., (2010): "Sex determination from measurements of the sternum and fourth rib using multislice computed tomography of the chest." Forensic Sci Int 197 (1-3): 120.e15.

Sidler, M.; Jackowski, C.; Dirnhofer, R. et al. (2007): Use of multislice computed tomography in disaster victim identification - advantages andlimitations. Forensic Sci Int.169:118-128.
Singh, J. \& Pathak, R. K. (2013): "Morphometric sexual dimorphism of human sternum in a north Indian autopsy sample: sexing efficacy of different statistical techniques and a comparison with other sexing methods." Forensic Sci Int. 228 (13):174.

Spradley, M. K.\& Jantz, R. L. (2011): "Sex estimation in forensic anthropology: skull versus postcranial elements." J Forensic Sci. 56 (2):289-96.

Teige, K. (1983): "[Morphometric studies of $\mathrm{x}$-rays of the sternum]." Z Rechtsmed 90 (3):199-204.

Torwalt, C. R. \& Hoppa, R. D. (2005): "A test of sex determination from measurements of chest radiographs." J Forensic Sci. 50 (4):785-90. 


$$
\begin{aligned}
& \text { تحديد الجنس من قياسات عظمه القص و الضلّع الرّابع (دراسه مستعرضه) باستخدام }
\end{aligned}
$$

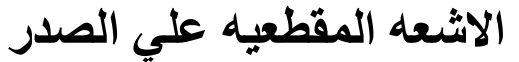

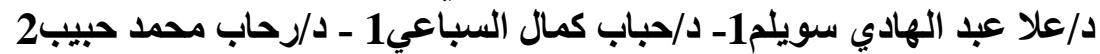

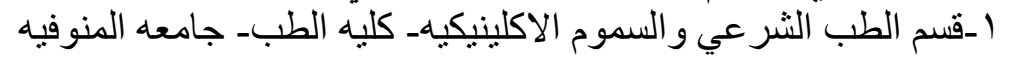

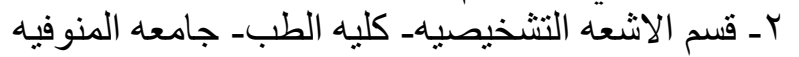

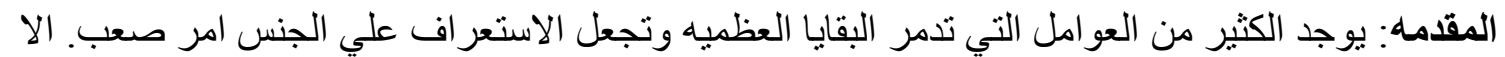

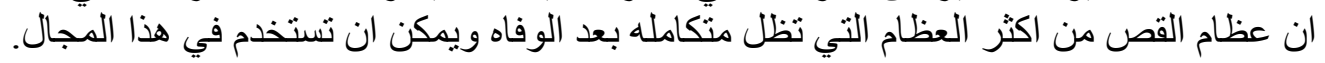

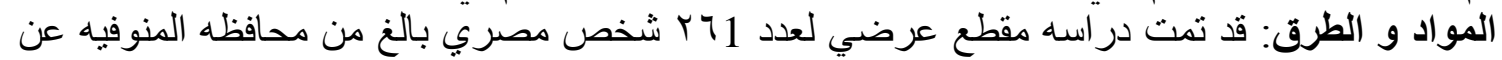

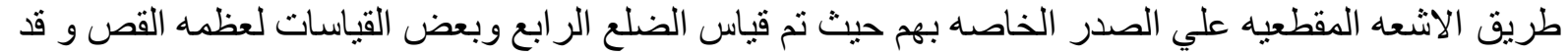

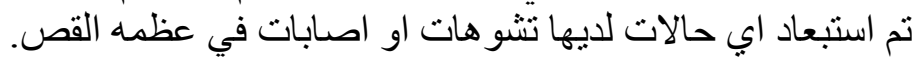

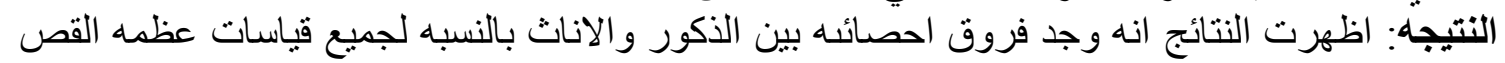

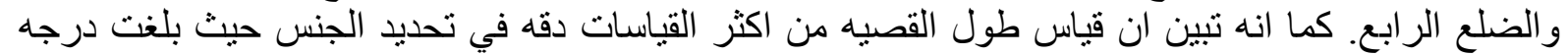

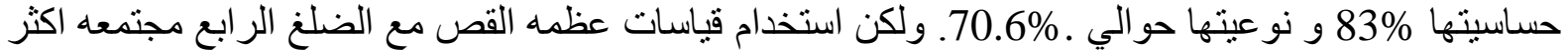

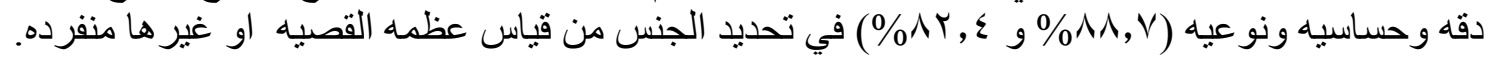

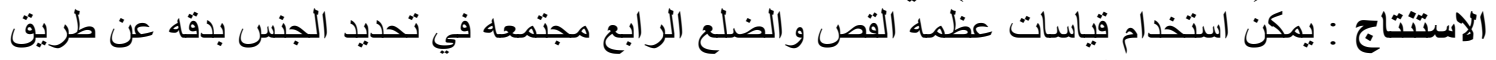
الاشعه المقطعيه ويعتبر قياس طول القصيه من اكثر القياسات المنفرده دقه في تحديد الجنس. التوصيه: نحن بحاجة إلى زيادة عدد الدراسات التي تجري باستخدام الاشعه مع التحات التحليلات المناسبة لها،

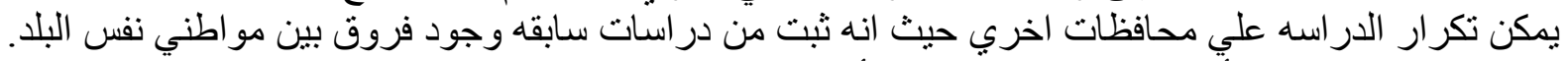

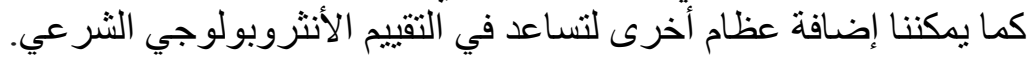
يوصي باستخدام معادله قياسات عظمه القص و الضلع الر ابع الناتجه في تحديد الجنس.

Sex determination $=-13.134+(\mathrm{SL} * 0.06)+(\mathrm{ML} * 0.111)+(\mathrm{MS} 1 * 0.045)+$ $(\mathrm{MS} 3 * 0.024)+\left(4\right.$ th $\left.\mathrm{rib}^{*} 0.092\right)$ 